\title{
Synergistic induction of lipid catabolism and anti-inflammatory lipids in white fat of dietary obese mice in response to calorie restriction and $\boldsymbol{n - 3}$ fatty acids
}

\author{
P. Flachs • R. Rühl • M. Hensler • P. Janovska • P. Zouhar • V. Kus • Z. Macek Jilkova • \\ E. Papp • O. Kuda • M. Svobodova • M. Rossmeisl • G. Tsenov • V. Mohamed-Ali • \\ J. Kopecky
}

Received: 10 January 2011 / Accepted: 31 May 2011 / Published online: 21 July 2011

(C) Springer-Verlag 2011

\begin{abstract}
Aims/hypothesis Calorie restriction is an essential component in the treatment of obesity and associated diseases. Longchain $n-3$ polyunsaturated fatty acids (LC $n-3$ PUFA) act as natural hypolipidaemics, reduce the risk of cardiovascular
\end{abstract}

Electronic supplementary material The online version of this article (doi:10.1007/s00125-011-2233-2) contains peer-reviewed but unedited supplementary material, which is available to authorised users.

P. Flachs $\cdot$ M. Hensler $\cdot$ P. Janovska $\cdot$ P. Zouhar $\cdot$ V. Kus $\cdot$

Z. Macek Jilkova $\cdot$ O. Kuda $\cdot$ M. Svobodova $\cdot$ M. Rossmeisl

J. Kopecky $(\bowtie)$

Department of Adipose Tissue Biology, Institute of Physiology

Academy of Sciences of the Czech Republic v.v.i.,

Videnska 1083,

14220 Prague, Czech Republic

e-mail: kopecky@biomed.cas.cz

R. Rühl $•$ E. Papp

Department of Biochemistry and Molecular Biology,

Laboratory of Nutritional Bioactivation and Bioanalysis,

University of Debrecen,

Debrecen, Hungary

\section{R. Rühl $\cdot$ E. Papp}

Apoptosis and Genomics Research Group of the Hungarian Academy of Science,

Debrecen, Hungary

\section{G. Tsenov}

Department of Developmental Epileptology, Institute of Physiology, Academy of Sciences of the Czech Republic v.v.i., Prague, Czech Republic

\section{Mohamed-Ali}

Adipokines and Metabolism Research Group,

University College London,

London, UK disease and could prevent the development of obesity and insulin resistance. We aimed to characterise the effectiveness and underlying mechanisms of the combination treatment with LC $n-3$ PUFA and $10 \%$ calorie restriction in the prevention of obesity and associated disorders in mice. Methods Male mice (C57BL/6J) were habituated to a cornoil-based high-fat diet (cHF) for 2 weeks and then randomly assigned to various dietary treatments for 5 weeks or 15 weeks: (1) cHF, ad libitum; (2) cHF with LC $n-3$ PUFA concentrate replacing $15 \%$ (wt/wt) of dietary lipids (cHF+F), ad libitum; (3) cHF with calorie restriction (CR; $\mathrm{cHF}+\mathrm{CR}$ ); and (4) $\mathrm{cHF}+\mathrm{F}+\mathrm{CR}$. Mice fed a chow diet were also studied.

Results We show that white adipose tissue plays an active role in the amelioration of obesity and the improvement of glucose homeostasis by combining LC $n$-3 PUFA intake and calorie restriction in cHF-fed mice. Specifically in the epididymal fat in the abdomen, but not in other fat depots, synergistic induction of mitochondrial oxidative capacity and lipid catabolism was observed, resulting in increased oxidation of metabolic fuels in the absence of mitochondrial uncoupling, while low-grade inflammation was suppressed, reflecting changes in tissue levels of anti-inflammatory lipid mediators, namely 15-deoxy- $\Delta^{12,15}$-prostaglandin $\mathrm{J}_{2}$ and protectin D1.

Conclusions/interpretation White adipose tissue metabolism linked to its inflammatory status in obesity could be modulated by combination treatment using calorie restriction and dietary LC $n-3$ PUFA to improve therapeutic strategies for metabolic syndrome.

Keywords 15-Deoxy- $\Delta^{12,15}$-prostaglandin $\mathrm{J}_{2} \cdot$ DHA . EPA · Fish oil · Metabolic syndrome $\cdot$ White adipose tissue 


\begin{tabular}{|c|c|}
\hline \multicolumn{2}{|c|}{ Abbreviations } \\
\hline $15 \mathrm{~d}-\mathrm{PGJ}_{2}$ & 15 -Deoxy- $\Delta^{12,15}$-prostaglandin $\mathrm{J}_{2}$ \\
\hline AA & Arachidonic acid \\
\hline AMPK & AMP-activated protein kinase \\
\hline $\mathrm{cHF}$ & Corn-oil-based high fat diet \\
\hline $\mathrm{cHF}+\mathrm{F}$ & $\begin{array}{l}\text { cHF diet supplemented with LC } n-3 \text { PUFA } \\
\text { concentrate }(15 \%[\mathrm{wt} / \mathrm{wt}] \text { of dietary lipids })\end{array}$ \\
\hline CLS & Crown-like structure \\
\hline $\mathrm{COX}$ & Cyclooxygenase \\
\hline $\mathrm{CyOX}$ & Cytochrome $c$ oxidase \\
\hline DHA & Docosahexaenoic acid \\
\hline EPA & Eicosapentaenoic acid \\
\hline FA & Fatty acid \\
\hline FASTED & Fasted state, specifically defined \\
\hline FCCP & $\begin{array}{l}\text { Carbonyl } \\
\text { cyanide- } p \text {-trifluoromethoxyphenylhydrazone }\end{array}$ \\
\hline LC $n-3$ & Long-chain $n-3$ \\
\hline LOX & Lipoxygenase \\
\hline $\mathrm{NF}-\mathrm{kB}$ & $\begin{array}{l}\text { Nuclear factor } \mathrm{k} \text { light-chain enhancer of } \\
\text { activated B cells }\end{array}$ \\
\hline MAC-2 & $\beta$-Galactoside-binding lectin \\
\hline PD1 & Protectin D1 \\
\hline PGC-1 $\alpha$ & $\operatorname{PPAR} \gamma$ coactivator $1 \alpha$ \\
\hline PLS-DA & Partial least squares-discriminant analysis \\
\hline $\operatorname{PPAR} \gamma$ & Peroxisome proliferator-activated receptor $\gamma$ \\
\hline PUFA & Polyunsaturated fatty acids \\
\hline RE-FED & Re-fed state, specifically defined \\
\hline SIRT1 & $\begin{array}{l}\text { Sirtuin } 1 \text { (silent mating type information } \\
\text { regulation } 2 \text {, homologue) } 1\end{array}$ \\
\hline TG & Triacylglycerol \\
\hline UCP1 & Uncoupling protein 1 \\
\hline WAT & White adipose tissue \\
\hline
\end{tabular}

\section{Introduction}

Intrinsic metabolic properties and secretory functions of white adipose tissue (WAT) have a major impact on the development of chronic morbidities associated with obesity, including type 2 diabetes, dyslipidaemia and hypertension. When (post)prandial plasma levels of NEFA and triacylglycerol (TG) exceed the storage capacity of WAT [1], other tissues including the liver and muscle become overloaded with lipids, which results in insulin resistance, the key event in the pathophysiology of metabolic syndrome [2]. The important role of WAT in energy homeostasis is underscored by the findings that WAT is one of the key organs affected by calorie restriction, the most effective strategy to prolong a healthy life in several species [3], and by the fact that accumulation of body fat can be reduced through upregulation of lipid catabolism in WAT [4-10]. The metabolism and secretory functions of WAT are also modulated by longchain (LC) n-3 polyunsaturated fatty acids (PUFA), namely eicosapentaenoic acid (EPA; 20:5 n-3) and docosahexaenoic acid (DHA; 22:6 n-3), which exert numerous beneficial effects on health, including improvements in lipid metabolism and prevention of obesity and diabetes [11], while decreasing the rate of fatal coronary heart disease in diabetic patients who have had a myocardial infarction [12]. The metabolic changes induced by both calorie restriction and LC $n$-3 PUFA include induction of mitochondrial biogenesis and lipid catabolism in WAT [3, 13].

Importantly, LC $n$-3 PUFA also decrease inflammation [14], including obesity-associated low-grade inflammation of WAT $[15,16]$, characterised by altered secretion patterns of adipokines, which contributes to insulin resistance [1]. The anti-inflammatory effects of LC $n-3$ PUFA probably depend on the formation of their active metabolites. These lipid mediators originate from either targeted enzymatic synthesis, such as resolvins and protectins [17, 18], or from non-enzymatic oxidation reactions $[19,20]$. They can act as ligands for surface receptors or can interact with signalling proteins including the transcription factors peroxisome proliferator-activated receptor $\gamma(\operatorname{PPAR} \gamma)$ and nuclear factor $\kappa$ light-chain enhancer of activated B cells (NF-KB) [19]. Notably, resolvins and protectins mediate the antiinflammatory and protective actions of LC $n-3$ PUFA in obesity-induced insulin resistance and hepatic steatosis [17, 21]. As LC $n-3$ PUFA and LC $n-6$ PUFA compete for common enzymatic pathways, a relatively small increase in the LC $n$-3 PUFA intake usually slows down synthesis of pro-inflammatory metabolites derived from arachidonic acid (AA; 20:4 n-6) [17, 18]. Given the complexity of factors contributing to the development of metabolic syndrome, its prevention and treatment requires strategies combining several approaches. Clinical studies suggest [22-24] that combining calorie restriction and LC $n-3$ PUFA intake may be helpful. As both treatments could promote fatty acid (FA) oxidation in WAT (see above), we have endeavoured in this study to establish whether lipid catabolism in WAT could be augmented by calorie restriction combined with LC $n$-3 PUFA intake. Our results in dietary obese mice show additive effects of calorie restriction and LC $n-3$ PUFA in the induction of mitochondrial biogenesis and lipid catabolism, occurring with a surprising specificity in intraabdominal WAT, which could contribute to the beneficial systemic effects of the combination treatment. The tissuespecificity could be explained by formation of antiinflammatory lipid mediators derived from both LC $n-3$ and LC $n-6$ PUFA. 


\section{Methods}

Animal treatment Male mice (C57BL/6J; Jackson Laboratory, ME, USA) were weaned onto standard laboratory chow (Chow; extruded R/M-H diet; Ssniff Spezialdiäten, Soest, Germany). Singly caged mice were habituated to a corn-oilbased high-fat diet (cHF; lipid content 35\%,wt/wt; [16]) for 2 weeks starting at 2 months of age and then randomly assigned for 5 weeks (four independent experiments) or 15 weeks (one experiment) to various dietary treatments (see electronic supplementary material [ESM] Fig. 1): (1) cHF, ad libitum; (2) cHF supplemented with LC $n$-3 PUFA concentrate (46\% wt/wt DHA, 14\% wt/wt EPA; product EPAX 1050 TG; EPAX, Alesund, Norway) replacing $15 \% \mathrm{wt} / \mathrm{wt}$ of dietary lipids (cHF+F), ad libitum; (3) cHF with restriction of energy intake - the ration was reduced by $10 \% \mathrm{wt} / \mathrm{wt}$ compared with mice fed ad libitum with the same type of diet (CR; cHF+ $\mathrm{CR}$ ); and (4) $\mathrm{cHF}+\mathrm{F}+\mathrm{CR}$. When indicated, plasma was collected by using tail bleeds during the FASTED to RE-FED transition (for the detailed definition of FASTED and RE-FED state, see ESM). An OGTT was performed in overnight-fasted mice as in Kuda et al. [16], except that glucose was administered by oral gavage. At the end of the treatment, mice were killed in a random fed state (between 08:00 hours and 10:00 hours).

Experiments were conducted according to the guidelines for the use and care of laboratory animals of the Institute of Physiology.

Tissue lipid content The tissue content of TG was estimated in ethanolic $\mathrm{KOH}$ tissue solubilisates [25].

Energy expenditure and metabolic flexibility Energy expenditure and fuel partitioning were evaluated using the indirect calorimetry system INCA (Somedic, Horby, Sweden) at $30^{\circ} \mathrm{C}$ [26]. Metabolic flexibility was assessed as a maximal induction in RQ $\left(\dot{V} \mathrm{CO}_{2} / \dot{V} \mathrm{O}_{2}\right)$ values in response to a glucose load $(0.45 \mathrm{ml}$ of $50 \%$ [wt/vol.] D-glucose $)$ administered by intragastric gavage to overnight $(12 \mathrm{~h})$ fasted animals. The induction was calculated from RQ values averaged over $60 \mathrm{~min}$ intervals before and after the gavage (ESM Fig. 2).

Physical activity Animal behaviour was recorded by video camera and analysed off-line (see ESM).

Plasma variables Levels of glucose, NEFA, TG, leptin, total adiponectin, IL-6, $\beta$-hydroxybutyrate and insulin were determined in plasma $[16,27]$.

Gene expression Transcript levels were evaluated using quantitative real-time RT-PCR (see ESM).
Ex vivo biochemical analysis FA oxidation was measured using $\left[1-{ }^{14} \mathrm{C}\right]$ palmitate in fragments of epididymal fat or gastrocnemius muscle or whole soleus muscle [28], in isolated adipocytes [29], and in hepatocytes isolated from mice following the in vivo treatment [30]. The rate of FA synthesis in epididymal fat was measured by incorporation of ${ }^{3} \mathrm{H}_{2} \mathrm{O}$ into saponifiable FAs [9]. Mitochondrial respiration was evaluated using high-resolution respirometry in digitonin-permeabilised adipocytes [29] using OROBOROS Oxygraph-2k (Oroboros Instruments, Innsbruck, Austria; see Fig. 4c,d legend).

Activity of cytochrome $c$ oxidase and cytochrome $b$ and protein content Crude membrane fraction was used to evaluate activity of cytochrome $c$ oxidase (CyOX) spectrophotometrically [10] and to quantify cytochrome $b$ using a pseudo-dual-wavelength spectrophotometry [29].

Immunohistochemical analysis Morphometry of adipocytes was performed (5 $\mu \mathrm{m}$ sections) using Lucia IMAGE software (Laboratory Imaging, Prague, Czech Republic). In the case of epididymal fat, sections were processed to detect $\beta$-galactoside-binding lectin (MAC-2) and perilipin [16].

Lipidomic analysis In total, 24 lipid molecular species were quantified in epididymal fat and liver extracts using HPLC MS-MS analysis [31] (see ESM).

Statistical analysis All values are presented as means \pm SEM. Comparisons were judged to be significant at $p \leq 0.05$ (see ESM).

\section{Results}

Combination treatment counteracts development of obesity and accumulation of ectopic fat Feeding mice a cHF diet increased their body weight (Fig. 1a). Either $\mathrm{cHF}+\mathrm{F}$ or $\mathrm{cHF}+\mathrm{CR}$ treatment partially prevented the $\mathrm{cHF}$-induced obesity, while the combination treatment $(\mathrm{cHF}+\mathrm{F}+\mathrm{CR})$ provided full protection, as shown by the treatments lasting either 5 weeks (Fig. 1a and Table 1) or 15 weeks (see legend to Fig. 1). As already described [13, 30], food consumption was not affected by dietary LC $n-3$ PUFA (Table 1). Physical activity, evaluated after 3 weeks of the treatment (ESM Fig. 1) as total distance travelled and total duration of moving per $4 \mathrm{~h}$, was similar in the $\mathrm{cHF}$, cHF+ $\mathrm{F}$ and $\mathrm{cHF}+\mathrm{CR}$ mice, while it was lower in the $\mathrm{cHF}+\mathrm{F}+$ CR mice (Table 1). Prevention of dietary obesity by various treatments correlated with reduction of both adiposity and fat cell size in all fat depots analysed at 

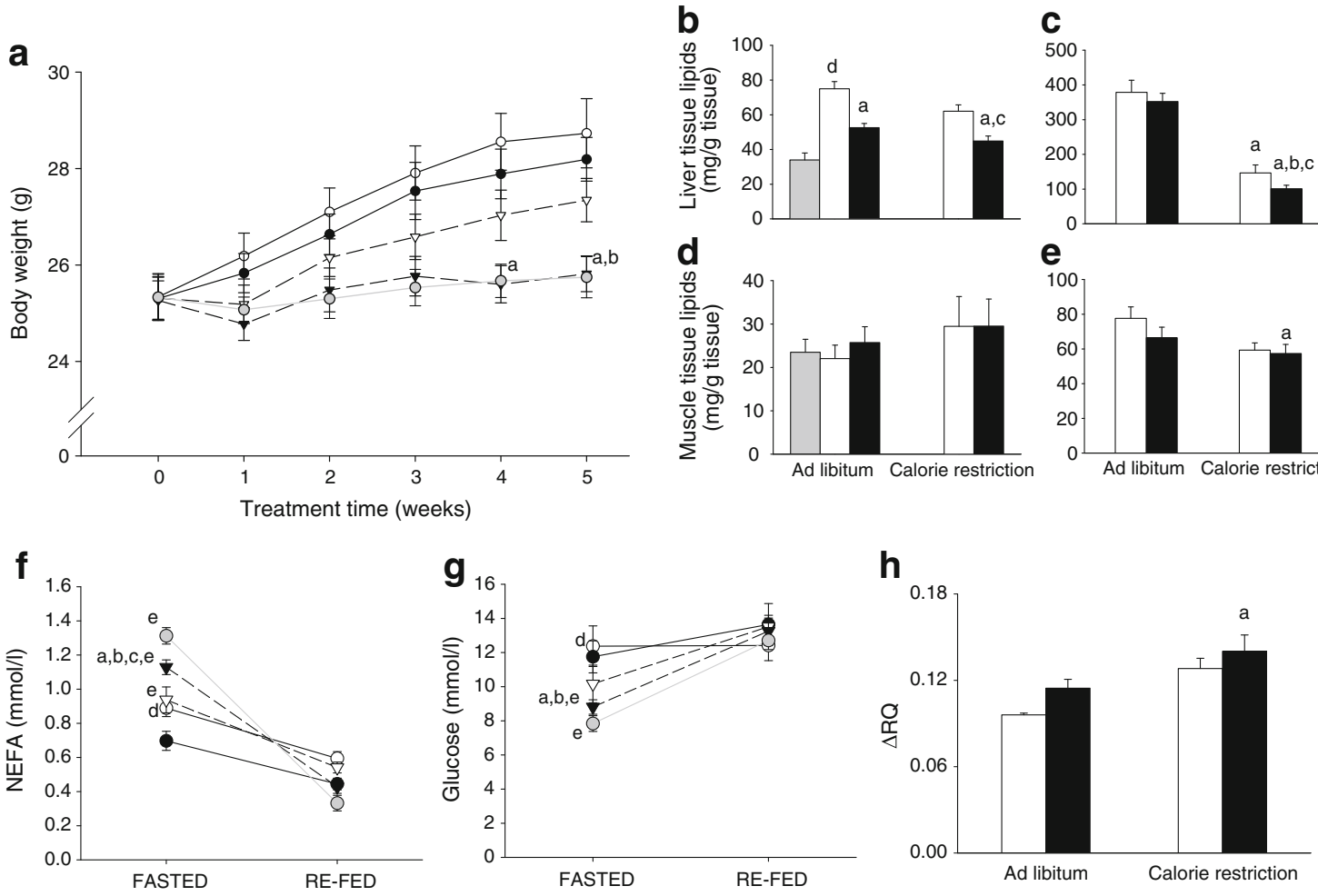

Fig. 1 Prevention of diet-induced obesity, hepatic steatosis, and metabolic inflexibility. a Body weight of mice; week 0 , start of the differential dietary treatment. Results from a typical experiment $(n=$ 10; see also Table 1). White circles, cHF; black circles, $\mathrm{cHF}+\mathrm{F}$; white triangles, $\mathrm{cHF}+\mathrm{CR}$; black triangles, $\mathrm{cHF}+\mathrm{F}+\mathrm{CR}$; grey circles, Chow. Five independent short-term ( 5 weeks) and one long-term (15 weeks) experiments were performed with similar results (not shown). After 15 weeks, body weights in mice fed different diets were as followed: $\mathrm{cHF}, 42.7 \pm 1.2 \mathrm{~g} ; \mathrm{cHF}+\mathrm{F}, 36.8 \pm 1.9 \mathrm{~g} ; \mathrm{cHF}+\mathrm{CR}, 34.7 \pm 2.5 \mathrm{~g} ; \mathrm{cHF}+$ $\mathrm{F}+\mathrm{CR}, 33.1 \pm 0.8 \mathrm{~g} ; p<0.05$ vs cHF for all the treatments. b-e Ectopic lipid accumulation in liver $(\mathbf{b}, \mathbf{c})$ and gastrocnemius muscle $(\mathbf{d}, \mathbf{e})$ after 5 weeks $(\mathbf{b}, \mathbf{d})$ or 15 weeks $(\mathbf{c}, \mathbf{e})$ of the treatment; $n=10$. Data for the Chow-fed mice are shown only for week 5 , but similar values at week 15 should be expected [16]. NEFA (f) and (g) glucose levels in plasma

5 weeks (Table 1). Significant differences in both variables were observed between the $\mathrm{cHF}$ mice and the $\mathrm{cHF}+\mathrm{F}+\mathrm{CR}$ mice, with the strongest effects elicited in the epididymal fat (Table 1). Feeding of the cHF diet induced accumulation of lipids in the liver and skeletal muscle. In the liver, all the treatments decreased TG accumulation and the effect of LC $n$-3 PUFA was stronger at 5 weeks (Fig. 1b) than at 15 weeks (Fig. 1c). In response to the longer treatment, the maximal reduction of $\mathrm{TG}$ accumulation in skeletal muscle was observed in the case of $\mathrm{cHF}+\mathrm{F}+\mathrm{CR}$ mice (Fig. 1e).

Combination treatment improves lipid and glucose homeostasis and preserves metabolic flexibility After 5 weeks of the treatment and in the ad libitum fed state, plasma TG levels were strongly reduced through either LC $n-3$ PUFA or calorie restriction alone, and even more with the combina-
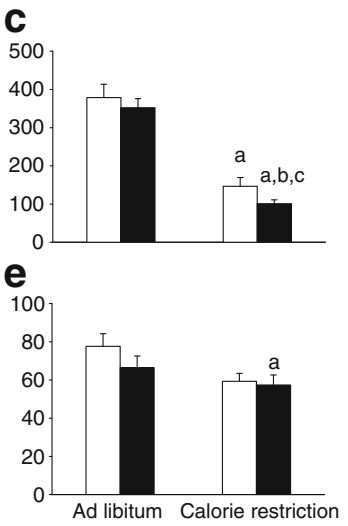

after 4 weeks of the treatment, measured in either the FASTED or REFED state (see ESM; $n=10$ ). White circles, cHF; black circles, $\mathrm{cHF}+\mathrm{F}$; white triangles, $\mathrm{cHF}+\mathrm{CR}$; black triangles, $\mathrm{cHF}+\mathrm{F}+\mathrm{CR}$; grey circles, Chow. h During the fourth week of the treatment, metabolic flexibility was assessed as a maximal induction in RQ values in response to a glucose load administered by intragastric gavage to animals fasted overnight $(12 \mathrm{~h})(n=9-10)$. White bars, $\mathrm{cHF}$ or $\mathrm{cHF}+$ $\mathrm{CR}$ diet; black bars, $\mathrm{cHF}+\mathrm{F}$ or $\mathrm{cHF}+\mathrm{F}+\mathrm{CR}$. Data from an independent experiment using the Chow-fed mice showed $\triangle \mathrm{RQ}=$ $0.15 \pm 0.01(n=9)$. For details, see ESM Fig. 2 and ESM Table 1. Data are means \pm SEM. ${ }^{\mathrm{a}, \mathrm{b}, \mathrm{c}}$ Significant difference (ANOVA) compared with $\mathrm{cHF}, \mathrm{cHF}+\mathrm{F}$, and $\mathrm{cHF}+\mathrm{CR}$, respectively; ${ }^{\mathrm{d}}$ significant difference $(t$ test) compared with Chow-fed mice ${ }^{\text {e }}$ significant difference (repeatedmeasures ANOVA) between the FASTED and RE-FED states

tion treatment (Table 1). This hypolipidaemic effect was negatively correlated with the effect of the treatments on plasma $\beta$-hydroxybutyrate, the marker of lipid catabolism. Glucose levels in plasma were similar in all the groups; however, insulin levels were decreased by $\mathrm{cHF}+\mathrm{CR}$ treatment and even more by the $\mathrm{cHF}+\mathrm{F}+\mathrm{CR}$ treatment (Table 1). In this respect, $\mathrm{cHF}+\mathrm{F}$ exerted a smaller but still significant effect. In the fasted state (Fig. 1g), the plasma concentration of glucose was lowered in response to calorie restriction, independent of dietary LC $n-3$ PUFA, with a trend for the lowest value in the $\mathrm{cHF}+\mathrm{F}+\mathrm{CR}$ mice. Levels of adiponectin were increased by $\mathrm{cHF}+\mathrm{F}$ to a similar extent in mice with free access to food and in the mice with restricted energy intake (Table 1), also in agreement with our previous findings [27]. As expected from the effects of treatments on adiposity, leptin levels tended to be reduced by $\mathrm{cHF}+\mathrm{F}$ and were significantly lowered by calorie 
Table 1 Body weight gain, food consumption, physical activity, organ weights, size of adipocytes and plasma variables in mice

All the variables were evaluated after 5 weeks of the treatment, except for physical activity, which was evaluated during week 4 and is represented by the total distance moved and moving time during both time intervals of the measurement $(2 \mathrm{~h}$ during light phase and $2 \mathrm{~h}$ during dark phase, see Methods). In the case of WAT, subcutaneous dorsolumbar, epididymal and mesenteric depots were collected. Tissue dissection and plasma collection were performed in random-fed state (between 08:00 hours and 10:00 hours)

Data are means \pm SEM; $n=10$

a,b,c Significant differences (ANOVA) compared with $\mathrm{cHF}$, $\mathrm{cHF}+\mathrm{F}$, and $\mathrm{cHF}+\mathrm{CR}$, respectively

\begin{tabular}{|c|c|c|c|c|}
\hline Variable & $\mathrm{cHF}$ & $\mathrm{cHF}+\mathrm{F}$ & $\mathrm{cHF}+\mathrm{CR}$ & $\mathrm{cHF}+\mathrm{F}+\mathrm{CR}$ \\
\hline Body weight gain (g) & $3.7 \pm 0.5$ & $2.9 \pm 0.6$ & $2.1 \pm 0.3^{\mathrm{a}}$ & $0.8 \pm 0.2^{\mathrm{a}, \mathrm{b}, \mathrm{c}}$ \\
\hline Food consumption (kJ/day per animal) & $74.6 \pm 0.6$ & $73.7 \pm 1.8$ & $67.1 \pm 0.5^{\mathrm{a}, \mathrm{b}}$ & $66.3 \pm 1.6^{\mathrm{a}, \mathrm{b}}$ \\
\hline \multicolumn{5}{|l|}{ Physical activity } \\
\hline Total distance moved (m) & $236 \pm 22$ & $231 \pm 65$ & $200 \pm 19$ & $152 \pm 19^{\mathrm{a}}$ \\
\hline Moving time (s) & $3668 \pm 432$ & $3424 \pm 775$ & $2974 \pm 359$ & $2204 \pm 362^{\mathrm{a}}$ \\
\hline \multicolumn{5}{|l|}{ Epididymal fat } \\
\hline Weight (mg) & $624 \pm 74$ & $566 \pm 90$ & $408 \pm 58$ & $262 \pm 26^{\mathrm{a}, \mathrm{b}}$ \\
\hline Adipocyte area $\left(\mu \mathrm{m}^{2}\right)$ & $2395 \pm 147$ & $1920 \pm 160$ & $1851 \pm 300$ & $1690 \pm 152^{\mathrm{a}}$ \\
\hline \multicolumn{5}{|l|}{ Mesenteric fat } \\
\hline Weight (mg) & $298 \pm 31$ & $277 \pm 19$ & $268 \pm 22$ & $205 \pm 16^{\mathrm{a}, \mathrm{b}}$ \\
\hline Adipocyte area $\left(\mu \mathrm{m}^{2}\right)$ & $1217 \pm 84$ & $1136 \pm 136$ & $1315 \pm 153$ & $997 \pm 108^{\mathrm{a}, \mathrm{c}}$ \\
\hline \multicolumn{5}{|l|}{ Subcutaneous fat } \\
\hline Weight (mg) & $284 \pm 26$ & $269 \pm 21$ & $233 \pm 20$ & $208 \pm 10^{\mathrm{a}}$ \\
\hline Adipocyte area $\left(\mu \mathrm{m}^{2}\right)$ & $1356 \pm 60$ & $1055 \pm 69^{\mathrm{a}}$ & $1188 \pm 2$ & $1069 \pm 124^{\mathrm{a}}$ \\
\hline \multicolumn{5}{|l|}{ Interscapular brown fat } \\
\hline Weight (mg) & $173 \pm 10$ & $121 \pm 5^{\mathrm{a}}$ & $119 \pm 4.8^{\mathrm{a}}$ & $76 \pm 5^{\mathrm{a}, \mathrm{b}, \mathrm{c}}$ \\
\hline \multicolumn{5}{|l|}{ Liver } \\
\hline Weight (mg) & $1148 \pm 59$ & $1233 \pm 18$ & $1134 \pm 26$ & $1009 \pm 36^{\mathrm{b}}$ \\
\hline \multicolumn{5}{|l|}{ Plasma } \\
\hline TG (mmol/l) & $1.24 \pm 0.11$ & $0.62 \pm 0.06^{\mathrm{a}}$ & $0.65 \pm 0.06^{\mathrm{a}}$ & $0.35 \pm 0.05^{\mathrm{a}, \mathrm{b}, \mathrm{c}}$ \\
\hline$\beta$-Hydroxybutyrate $(\mathrm{mmol} / \mathrm{l})$ & $0.09 \pm 0.01$ & $0.13 \pm 0.02^{\mathrm{a}}$ & $0.20 \pm 0.01^{\mathrm{a}, \mathrm{b}}$ & $0.28 \pm 0.02^{\mathrm{a}, \mathrm{b}, \mathrm{c}}$ \\
\hline Glucose $(\mathrm{mmol} / \mathrm{l})$ & $17.2 \pm 0.5$ & $17.0 \pm 0.4$ & $17.4 \pm 0.5$ & $15.5 \pm 0.8$ \\
\hline Insulin (pmol/1) & $300 \pm 35$ & $219 \pm 37^{\mathrm{a}}$ & $57 \pm 5^{\mathrm{a}, \mathrm{b}}$ & $35 \pm 9^{\mathrm{a}, \mathrm{b}, \mathrm{c}}$ \\
\hline Adiponectin $(\mu \mathrm{g} / \mathrm{ml})$ & $8.9 \pm 0.3$ & $12.1 \pm 0.5^{\mathrm{a}}$ & $9.3 \pm 0.2^{\mathrm{b}}$ & $11.1 \pm 0.5^{\mathrm{a}, \mathrm{c}}$ \\
\hline Leptin (ng/ml) & $77.2 \pm 7.6$ & $66.2 \pm 8.3^{\mathrm{a}}$ & $15.5 \pm 1.7^{\mathrm{a}, \mathrm{b}}$ & $5.3 \pm 0.7^{\mathrm{a}, \mathrm{b}, \mathrm{c}}$ \\
\hline
\end{tabular}

restriction, with the $\mathrm{cHF}+\mathrm{F}+\mathrm{CR}$ mice showing the lowest leptin levels (Table 1).

To characterise whole-body metabolic flexibility, which is associated with insulin sensitivity [2,32], the metabolic response to the FASTED/RE-FED transition was also analysed by assessing plasma levels of NEFA and glucose after 4 weeks of the treatment (Fig. 1f,g and ESM Fig. 1). Only in the FASTED, and not in the RE-FED state, did the metabolite levels differ between groups. Among the mice fed cHF-based diets, the $\mathrm{cHF}+\mathrm{F}+\mathrm{CR}$ mice showed the highest NEFA and the lowest glucose levels, while exhibiting the largest differences in plasma levels of both metabolites in response to the re-feeding. In fact, the cHF+ $\mathrm{F}+\mathrm{CR}$ treatment normalised the metabolic response when compared with the Chow-fed mice (Fig. 1f,g). In contrast, the cHF mice showed the lowest NEFA and the highest glucose levels in fasted state, with a minimum response to the FASTED/RE-FED transition observed with both metabolites (Fig. 1f,g). Indirect calorimetry was performed after 3 weeks of the treatment (ESM Figs 1 and 2) to characterise metabolic flexibility, as well as whole-body capacity to use carbohydrate and lipid fuels (Fig. 1h). When metabolic flexibility was expressed as maximal induction of RQ in response to the intragastric gavage of glucose, the combination treatment preserved metabolic flexibility better than any of the treatments applied separately. No effect of any of the treatments on energy expenditure, assessed as oxygen consumption $\left(\dot{V} \mathrm{O}_{2}\right) /$ animal, was observed either before or after the glucose gavage (ESM Fig. 2 and ESM Table 1).

To further characterise changes in glucose homeostasis, fasted plasma was analysed (Fig. 2a,b) and an OGTT was performed (Fig. 2c and ESM Fig. 3) after 3-4 weeks of treatment (ESM Fig. 1). Compared with cHF diet, only the combination treatment significantly decreased fasted insulinaemia and HOMA index (Fig. 2a,b). Specifically in mice subjected to calorie restriction, glucose levels were increased in response to overnight fasting, which preceded the glucose tolerance test (ESM Fig. 3). Feeding cHF diet resulted in glucose intolerance (Fig. 2c), while the deterioration of glucose homeostasis was prevented by the combination treatment with the other treatments tending to exert similar effects. In addition, insulin levels estimated in plasma during the test, $30 \mathrm{~min}$ after the glucose gavage, revealed the protective effect of the combination treatment $(220 \pm 51,296 \pm 37$, and $253 \pm 41 \mathrm{pmol}$ insulin/l in the Chowfed, $\mathrm{cHF}$ and $\mathrm{cHF}+\mathrm{F}+\mathrm{CR}$ mice, respectively). Ex vivo analysis of insulin-stimulated de novo FA synthesis in 
a

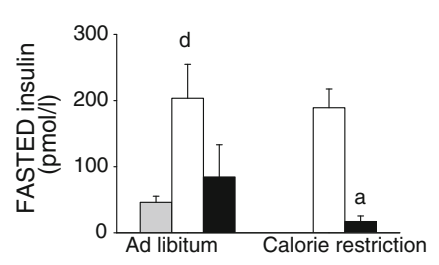

b

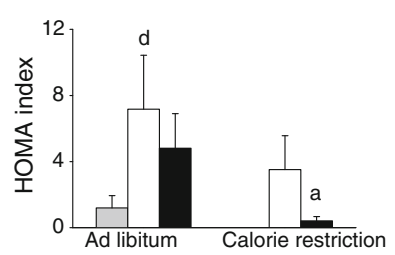

Fig. 2 Improvement of glucose homeostasis. a Insulin levels in plasma and b HOMA index of insulin resistance after 4 weeks of the treatment, calculated (see ESM) from the insulin levels (see a) and glycaemia measured in the fasted state (see Fig. 1g); c OGTT after 3 weeks of treatment $(0.5 \mathrm{ml} 30 \%$ [wt/vol.] D-glucose in water; see ESM Fig. 3). The results are expressed as AUC values; d ex vivo analysis of de novo FA synthesis in epididymal fat after 5 weeks of the

epididymal fat after 5 weeks of treatment showed an increased rate of FA synthesis due to either LC $n$-3 PUFA or calorie restriction alone, and a synergistic induction in response to the combination treatment (Fig. 2d).

Synergistic induction of genes of mitochondrial biogenesis and lipid catabolism in epididymal fat Based on the

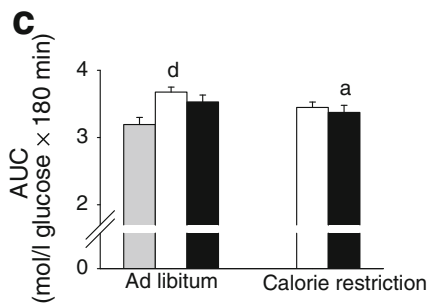

d

treatment, measured in the presence of insulin $(80 \mu \mathrm{U} / \mathrm{ml})$ and expressed as dpm ${ }^{3} \mathrm{H}$ incorporated to saponifiable FAs/mg tissue. White bars, $\mathrm{cHF}$ or $\mathrm{cHF}+\mathrm{CR}$; black bars, $\mathrm{cHF}+\mathrm{F}$ or $\mathrm{cHF}+\mathrm{F}+\mathrm{CR}$; grey bars, Chow. Data are means \pm SEM. ${ }^{\text {a,b,c }}$ Significant difference (ANOVA) compared with $\mathrm{cHF}, \mathrm{cHF}+\mathrm{F}$, and $\mathrm{cHF}+\mathrm{CR}$, respectively; $\mathrm{d}_{\text {significant difference }(t \text { test) compared with Chow-fed mice }}$

previous results showing induction of mitochondria and lipid catabolism by LC $n$-3 PUFA [13] and calorie restriction [3], we investigated gene expression in WAT, interscapular brown fat, liver and muscle (Fig. 3a-e). In epididymal WAT (Fig. 3a), the analysis revealed a strong induction of PPAR $\gamma$ co-activator $1 \alpha(P g c-1 \alpha$ [also known as Ppargcla]), peroxisome proliferator-activated receptor $\alpha$
Fig. 3 Specific induction of mitochondrial genes in epididymal fat. Quantitative real-time RT-PCR data showing relative levels of gene expression $(\mathrm{cHF}=$ 1) in epididymal (a) and subcutaneous (b) WAT, interscapular brown fat (c), liver (d), and gastrocnemius muscle (e) after 5 weeks of the treatment. Data are means \pm SEM; $n=10$; white bars, cHF; black bars, $\mathrm{cHF}+\mathrm{F}$; light grey bars, $\mathrm{cHF}+\mathrm{CR}$; dark grey bars, $\mathrm{cHF}+\mathrm{F}+\mathrm{CR}$;

${ }_{a, b, c}$ Significant difference (ANOVA) compared with cHF, $\mathrm{cHF}+\mathrm{F}$ and $\mathrm{cHF}+\mathrm{CR}$, respectively. An independent experiment showed no difference in either Pgc-1 $\alpha$ or Ppar $\alpha$ expression in epididymal fat between the $\mathrm{cHF}$ and the Chow-fed mice (the $\mathrm{cHF} / \mathrm{Chow}$ ratio of the $\mathrm{Pgc}$ $1 \alpha$ and Ppar $\alpha$ transcript levels was $1.08 \pm 0.05$ and $1.04 \pm 0.08$, respectively; $n=6$ ). All analyses were performed after 5 weeks of treatment

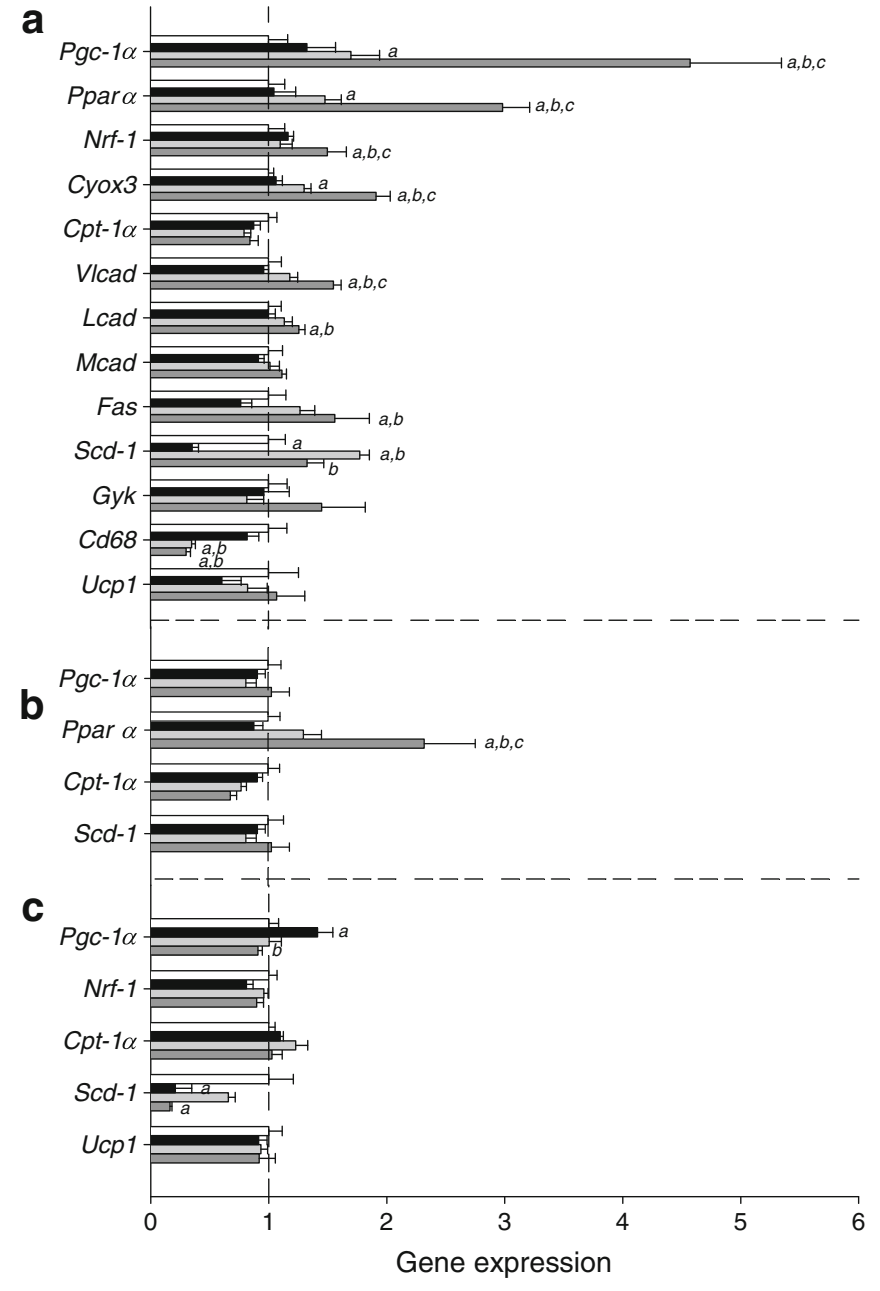

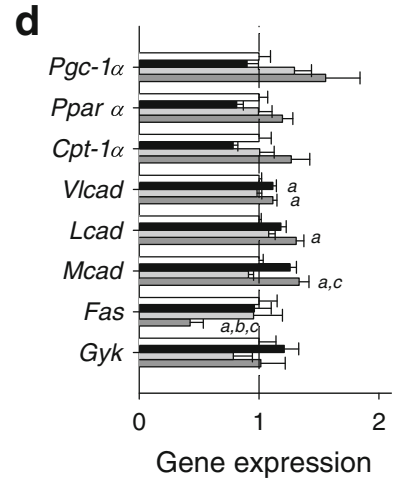

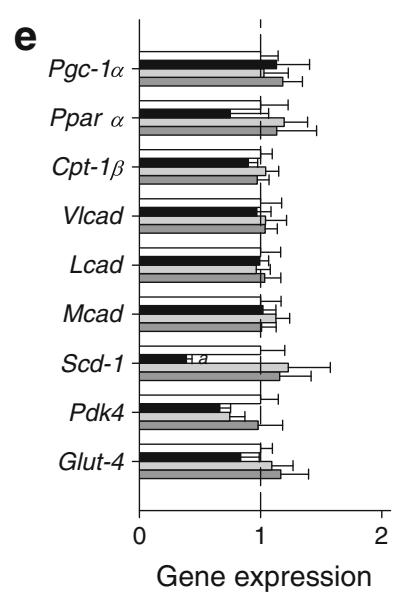


a

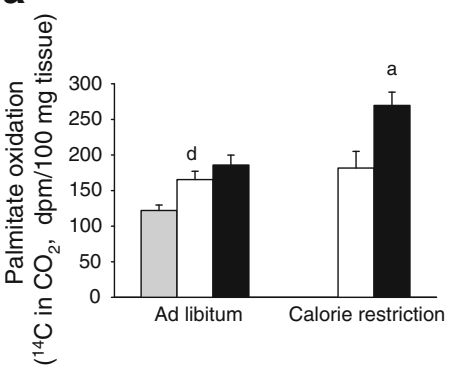

b

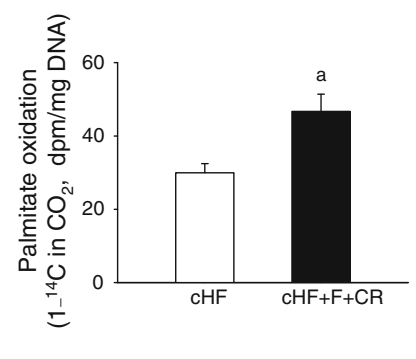

C

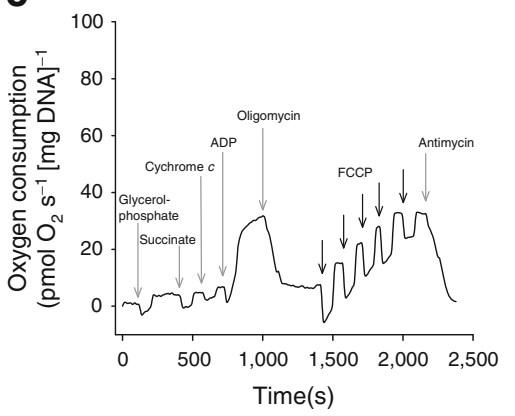

d

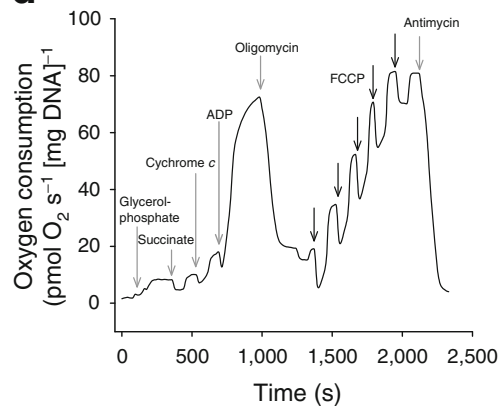

e

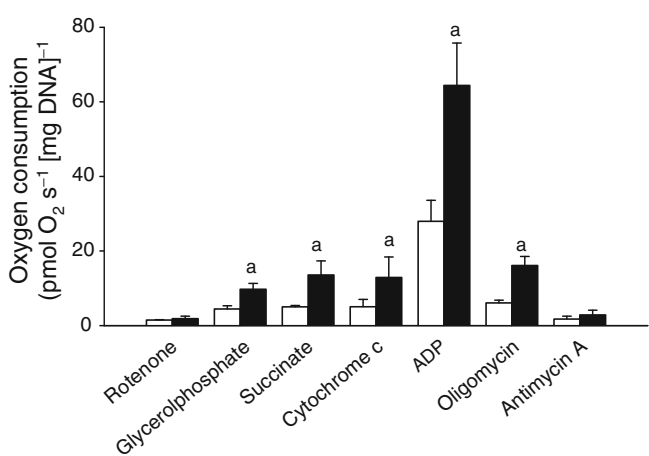

Fig. 4 Induction of fatty acid oxidation and mitochondrial oxidative capacity in epididymal fat. a Oxidation of $\left[1-{ }^{14} \mathrm{C}\right]$ palmitate into $\mathrm{CO}_{2}$ by tissue fragments. Data are means $\pm \mathrm{SEM} ; n=10$. White bars, $\mathrm{cHF}$ or $\mathrm{cHF}+$ $\mathrm{CR}$; black bars, $\mathrm{cHF}+\mathrm{F}$ or $\mathrm{cHF}+\mathrm{F}+\mathrm{CR}$; grey bars, Chow. ${ }^{\mathrm{a}}$ Significant difference (ANOVA) compared with cHF; ${ }^{\mathrm{d}}$ significant difference $(t$ test) compared with Chow-fed mice. b Oxidation of $\left[1-{ }^{14} \mathrm{C}\right]$ palmitate into $\mathrm{CO}_{2}$ by freshly isolated adipocytes. Data are means \pm SEM; $n=8$. ${ }^{\text {a Significant }}$ difference ( $t$ test). $\mathbf{c}, \mathbf{d}, \mathbf{e}$ Evaluation of mitochondrial respiratory capacity and oxidative phosphorylation in permeabilised adipocytes isolated from epididymal fat of the $\mathrm{cHF}$ and $\mathrm{cHF}+\mathrm{F}+\mathrm{CR}$ mice using multiple substrateinhibitor titration respirometry. c, $\mathbf{d}$ Representative oxygen flux curves (c $\mathrm{cHF}$; $\mathbf{d} \mathrm{cHF}+\mathrm{F}+\mathrm{CR})$. Adipocyte added in suspension $(0.2 \mathrm{ml})$ to $2 \mathrm{ml}$ incubation medium $(10 \mathrm{mmol} / \mathrm{l}$ Tris- $\mathrm{HCl}, 80 \mathrm{mmol} / \mathrm{l} \mathrm{KCl}, 3 \mathrm{mmol} /$ $1 \mathrm{MgCl}_{2}, 5 \mathrm{mmol} / 1 \mathrm{KH}_{2} \mathrm{PO}_{4}, 1 \mathrm{mmol} / \mathrm{l}$ EDTA and $1 \% \mathrm{wt} / \mathrm{wt}$ fatty-acidfree $\mathrm{BSA}, \mathrm{pH}$ 7.4) were permeabilised with the addition of $3 \mu \mathrm{l}$ digitonin

(Ppar [also known as Ppara]), nuclear respiratory factor 1 (Nrfl) and CyOX subunit 3 (Cyox3 [also known as Cox3]) by the combination treatment, suggesting increased biogenesis and oxidative capacity of mitochondria, independent of the type of diet (see legend for Fig. 3). Only Ppara expression was upregulated in subcutaneous WAT by the combination treatment, while no significant changes in the expression of the above gene cluster was observed in interscapular brown fat (Fig. 3c), liver (Fig. 3d) or skeletal muscle (Fig. 3e). Concerning the genes of $\beta$-oxidation such as very long-chain, long-chain and medium-chain acyl-CoA dehydrogenases (Vlcad [also known as Acadvl], Lcad [also known as Acadl] and Mcad [also known as Acadm], respectively), additive induction of Vlcad and Lcad was noted in the epididymal WAT (Fig. 3a), and a slight increase in the expression of the $\beta$-oxidation genes observed in response to $\mathrm{cHF}+\mathrm{F}$ or $\mathrm{cHF}+\mathrm{F}+\mathrm{CR}$ treatments in the liver
(10 $\mathrm{mg} / \mathrm{ml}$ DMSO), mitochondrial complex I was inhibited by $2 \mu \mathrm{l}$ of $1 \mathrm{mmol} / \mathrm{l}$ rotenone, and respiration was stimulated by successive additions of: (1) $20 \mu 11 \mathrm{~mol} / 1$ glycerol 3-phosphate; (2) $20 \mu \mathrm{l} 1 \mathrm{~mol} / \mathrm{l}$ succinate; and (3) $10 \mu 10.3 \mathrm{~mol} / \mathrm{l}$ ADP (before the ADP addition, mitochondrial integrity was tested by addition of $10 \mu \mathrm{l}$ of $4 \mathrm{mmol} / \mathrm{l}$ reduced cytochrome c). Subsequently, ATP synthase was inhibited by $2 \mu 1$ oligomycin $(4 \mathrm{mg} /$ $\mathrm{ml}$ ), respiration was re-activated by additions of uncoupler of oxidative phosphorylation (carbonyl cyanide- $p$-trifluoromethoxyphenylhydrazone; FCCP; $0.5 \mu \mathrm{l}$ of $1 \mathrm{mmol} / \mathrm{l} \mathrm{FCCP}$ at each addition), and finally, respiration was inhibited by $2 \mu \mathrm{l}$ of $5 \mathrm{mmol} / \mathrm{l}$ antimycin A (inhibitor of complex III). e Averaged values from respirometry $(n=4$; pooled samples from two animals). White bars, cHF; black bars, $\mathrm{cHF}+\mathrm{F}+\mathrm{CR}$. Data are means \pm SEM. a Significant difference (paired $t$ test) between the groups. All analyses were performed after 5 weeks of treatment

(Fig. 3d) but not in the muscle (Fig. 3e). FA synthase (Fas) was upregulated in epididymal WAT of the $\mathrm{cHF}+\mathrm{F}+\mathrm{CR}$ mice (Fig. 3a), but significant downregulation of Fas was observed in the liver of these animals (Fig. 3d). No induction of uncoupling protein 1 (Ucpl) by any of the treatments either in epididymal fat or in interscapular brown fat was detected (Fig. 3a,c).

Combination treatment induced FA oxidation and mitochondrial oxidative capacity in epididymal fat To confirm the synergistic induction of mitochondrial FA oxidation by LC n-3 PUFA and calorie restriction in epididymal fat, biochemical assessment was performed ex vivo after 5 weeks of the dietary treatment. First, $\left[1-{ }^{14} \mathrm{C}\right]$ palmitate oxidation was measured in fragments of epididymal fat. Feeding the cHF diet stimulated palmitate oxidation compared with Chow feeding, and this activity was further 
significantly stimulated only by the combination treatment, documenting a synergism between LC $n$-3 PUFA and calorie restriction in the induction of FA oxidation (Fig. 4a). Accordingly, adipocytes isolated from epididymal fat of the $\mathrm{cHF}+\mathrm{F}+\mathrm{CR}$ mice also exerted a higher DNAadjusted rate of palmitate oxidation compared with $\mathrm{cHF}$ mice (Fig. 4b). This analysis, as well as the analysis of mitochondrial function described below, was restricted to the comparison between the $\mathrm{cHF}$ mice and the $\mathrm{cHF}+\mathrm{F}+\mathrm{CR}$ mice, i.e. the two groups supposed to exhibit the largest differences in the metabolic variables.

Second, the activity of CyOX, the terminal component of the mitochondrial respiratory chain, and the content of cytochrome $b$ were evaluated in epididymal fat. In the $\mathrm{cHF}+\mathrm{F}+\mathrm{CR}$ mice, the CyOX activity was higher compared with cHF mice $(4.5 \pm 0.3$ vs $3.5 \pm 0.4 \mu \mathrm{mol}$ cytochrome $c$ oxidised $\min ^{-1} \mathrm{mg}$ protein $\left.{ }^{-1}, p<0.05\right)$, in accordance with the difference in the cytochrome $b$ content $(926 \pm 116$ vs $590 \pm 34 \mathrm{pmol} / \mathrm{mg}$ protein, $p<0.05)$.

Third, mitochondrial oxidative capacity was characterised in adipocytes using respirometry and adjusted to DNA content (Fig. 4c-e). Adipocytes from the $\mathrm{cHF}+\mathrm{F}+\mathrm{CR}$ mice exerted an approximately twofold higher rate of ADPdependent oxygen consumption in the presence of respiratory substrates glycerol-3-phosphate and succinate (state 3 respiration) compared with the cHF mice. This indicates a much higher oxidative capacity of adipose tissue mitochondria in the $\mathrm{cHF}+\mathrm{F}+\mathrm{CR}$ mice. In addition, a similar degree of inhibition of state 4 respiration by oligomycin (Fig. 4ce), similar respiratory control indexes (state $3 /$ state 4 ; cHF+ $\mathrm{F}+\mathrm{CR}, 5.54 \pm 1.13$ vs cHF, $5.57 \pm 1.15$ ), and a reversal of the inhibitory effect of oligomycin by carbonyl cyanide- $p$ trifluoromethoxyphenylhydrazone (FCCP, see Fig. 4c,d) indicated tight coupling between respiration and phosphorylation in the epididymal fat mitochondria of both groups.

To assess changes in lipid catabolism in the other tissues, palmitate oxidation was measured in isolated hepatocytes and in skeletal muscles ex vivo, following the 5 week treatment (ESM Table 2). The combination treatment, but not the other treatments, increased the hepatic FA oxidation compared with the cHF mice, but it had no effect on FA oxidation in muscle.

Combination treatment ameliorates low-grade adipose tissue inflammation induced by high-fat diet As LC n-3 PUFA prevented obesity-associated low-grade inflammation of WAT in mice $[15,16]$, we analysed the antiinflammatory action of LC $n-3$ PUFA in the context of mild restriction of energy intake. Immunohistochemical analysis of epididymal fat of various treatments revealed a reduced content of macrophages aggregated in crown-like structures (CLS) surrounding dead adipocytes [33] compared with the cHF mice. The macrophage infiltration was maximally reduced in mice subjected to the combination treatment
(Fig. 5a-c) and mRNA levels for the macrophage marker CD68 were decreased in the epididymal fat of all treatment groups compared with the cHF controls (Fig. 3a). Moreover, plasma levels of IL-6, a marker of systemic inflammation, were significantly reduced only by the combination treatment (Fig. 5d).

Specific induction of anti-inflammatory lipid mediators in epididymal fat To investigate the possible involvement of bioactive lipids derived from PUFA and modulating inflammation (see Introduction and Fig. 6), lipidomic analysis was performed in epididymal fat and in the liver. In total, 24 lipid species were quantified (ESM Table 3). Partial least-squares-discriminant analysis (PLS-DA) revealed the major discriminating lipid species between the groups. In WAT, but not in the liver, the first two PLS-DA components separated mice into four distinct groups corresponding to dietary treatments (ESM Figs 4 and 5). Following contribution-score analysis, the most important lipids were identified for each of the intervention groups. As shown in Fig. 7a,c,e and in ESM Table 3, the levels of AA, EPA and DHA in the free FA fraction of WAT were significantly higher in all treated groups compared with the cHF mice (except for AA in the ad libitum mice treated by LC $n-3$ PUFA). The $\mathrm{cHF}+\mathrm{F}+\mathrm{CR}$ treatment exerted the most a

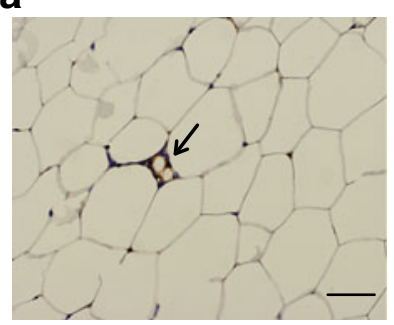

C

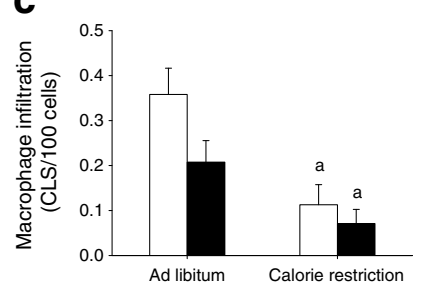

b

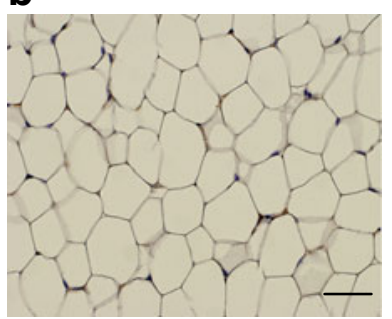

d

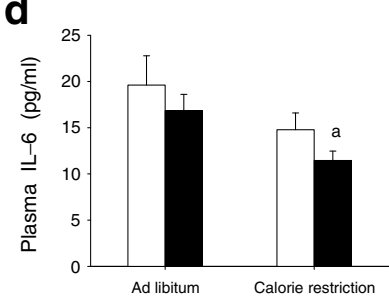

Fig. 5 Prevention of adipose tissue and systemic inflammation. Immunohistochemical analysis of epididymal fat of the cHF mice (a) and the $\mathrm{cHF}+\mathrm{F}+\mathrm{CR}$ mice (b) with visualised MAC-2 antigen (expressed on activated macrophages); arrow indicates aggregates of macrophages forming CLS, which surround dead adipocytes. c Relative count of CLS; $n=6$. d Plasma level of IL-6, marker of systemic inflammatory status. Data are means \pm SEM; $n=10$; white bars, $\mathrm{cHF}$ or $\mathrm{cHF}+\mathrm{CR}$; black bars, $\mathrm{cHF}+\mathrm{F}$ or $\mathrm{cHF}+\mathrm{F}+\mathrm{CR}$; ${ }^{\text {a }}$ Significant difference (ANOVA) compared with the cHF mice. The morphometry data are based on more than 1,000 cells taken randomly from six different areas per animal. All analyses were performed after 5 weeks of the treatment 
pronounced effect. In the liver, free EPA and DHA levels were significantly affected only by LC $n-3$ PUFA, independent of calorie restriction (Fig. 7d,f). In both tissues, the levels of primary monohydroxy metabolites derived from linoleic (HODE), AA (HETE), EPA (HEPE) and DHA (HDoHE) correlated with those of the corresponding FAs (Fig. 6). The lipoxygenase (LOX) products were the most abundant autacoids in both tissues of the cHF controls. Dietary supply of EPA and DHA triggered formation of LC $n-3$ PUFAderived metabolites in both tissues. The WAT-specific liberation of FAs from membrane phospholipids in response to calorie restriction resulted in the formation of lipid mediators derived from both LC $n-3$ and LC $n$-6 PUFA (Fig. 6). Only in WAT, dietary LC $n-3$ PUFA combined with calorie restriction synergistically increased the levels of protectin D1 (PD1; Fig. $7 \mathrm{~g}$ ), a well described anti-inflammatory lipid mediator derived from DHA, or PD1 isomers such as PDX. In accordance with a previous finding [18], resolvin E1 (derived from EPA) was below the level of detection. Unexpectedly, 15 -deoxy- $\Delta^{12,15}$ prostaglandin $\mathrm{J}_{2}\left(15 \mathrm{~d}-\mathrm{PGJ}_{2}\right)$, an anti-inflammatory mediator and potent PPAR $\gamma$ agonist derived from AA [34], was also synergistically upregulated by the combination treatment specifically in WAT (Fig. 7i).

\section{Discussion}

We show here that the combination treatment of dietary LC $n$-3 PUFA and mild calorie restriction is more effective than each of the treatments applied separately in the protection against obesity in mice. Pronounced induction of mitochondrial lipid catabolism and synergistic induction of antiinflammatory lipid mediators in WAT could contribute the systemic effects of the combination treatment (Fig. 8).

Our results demonstrate an improvement of metabolic flexibility by the combination treatment, based on both the

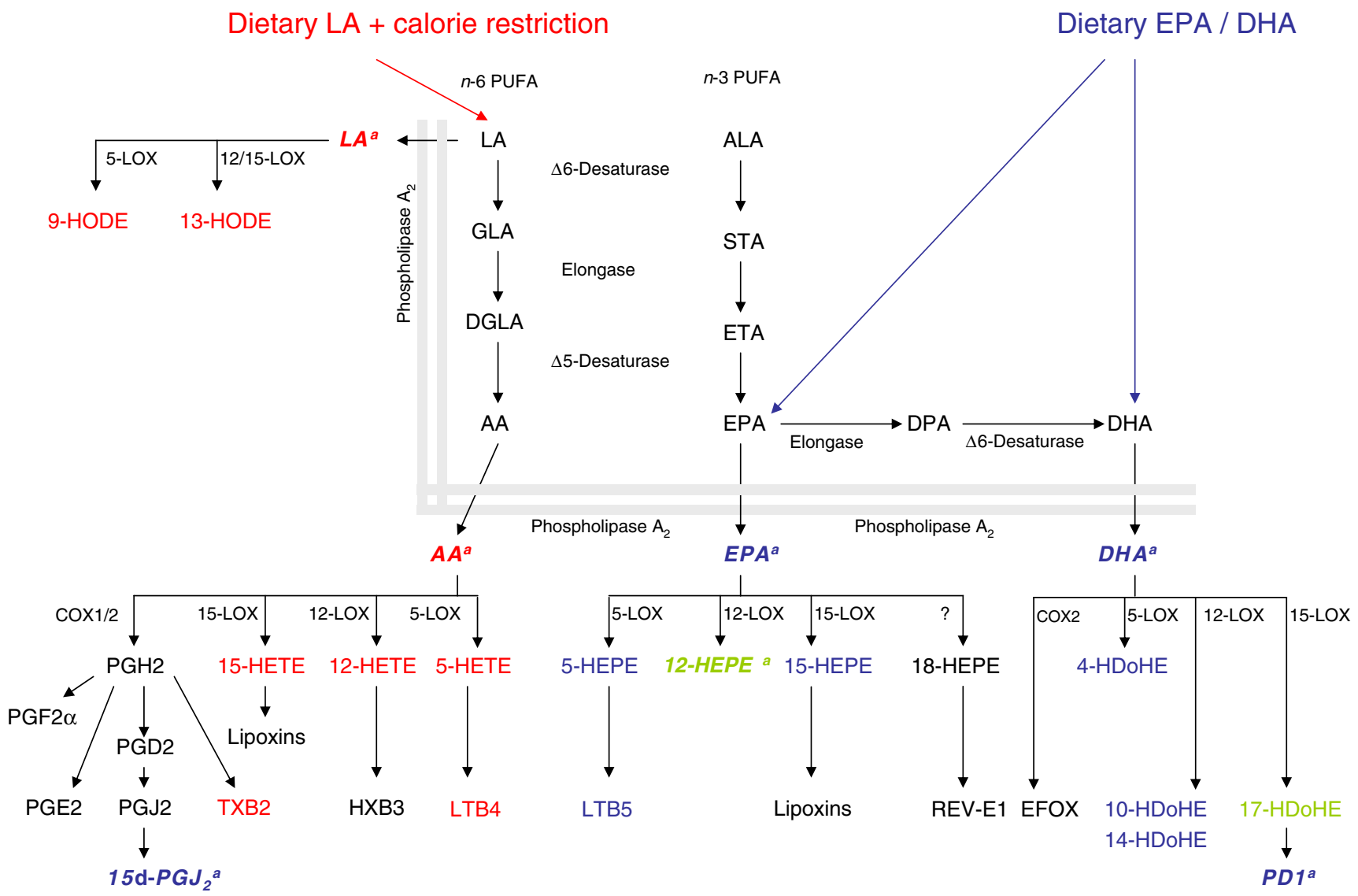

Fig. 6 Overview of the effects of calorie restriction, LC n-3 PUFA and the combination treatment on the levels of lipid mediators in epididymal fat. Scheme is based on the results of lipidomic analysis (see Fig. 7, ESM Table 3 and ESM Fig. 3). Significantly upregulated metabolites are marked by different colours; red colour, upregulated by calorie restriction; blue colour, upregulated by LC $n-3$ PUFA; green colour, upregulated by each of the treatments; ${ }^{a}$ synergistic upregulation by the combination treatment. Some pathways mentioned in this figure are speculative and not conclusively described. The scheme is inspired by Larsson et al. [50]. ALA, $\alpha$-linolenic acid (18:3n-3); DGLA, dihomo- $\gamma$-linolenic acid (20:3 $n$-6); EFOX, electrophilic oxoderivatives from DHA [19]; GLA, $\gamma$-linolenic acid (18:3 n-6); HXB3, hepoxilin B3; LA, linoleic acid (18:2 n-6); 5-,12-,15-LOX, 5,12,15lipoxygenase; LTB4/B5, leukotriene B4/B5; PD1, protectin D1; PG, prostaglandin; PLA 2 , phospholipase $\mathrm{A}_{2}$; Rev-E1, resolvin E1; TXB2, thromboxane $\mathrm{B} 2$ 
a

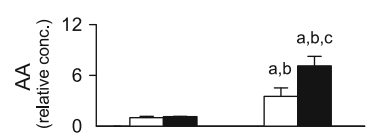

C

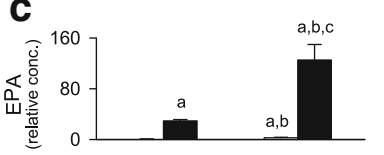

e

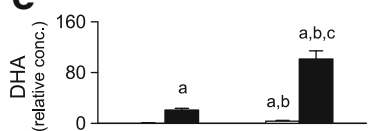

g

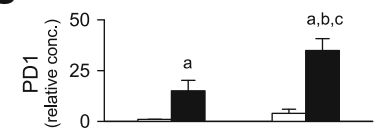

i

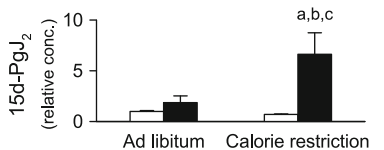

b

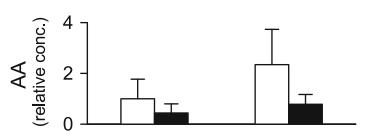

d

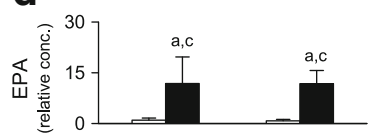

f

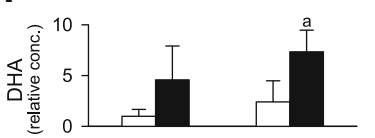

h

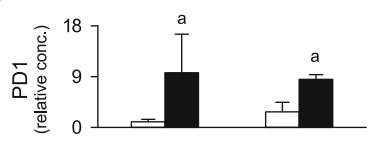

j

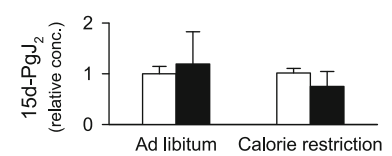

Fig. 7 Synergistic induction of anti-inflammatory lipid mediators in adipose tissue. $\mathbf{a}-\mathbf{j}$ Selected results of lipidomic HPLC MS-MS analysis of epididymal fat $(\mathbf{a}, \mathbf{c}, \mathbf{e}, \mathbf{g}, \mathbf{i})$ and liver $(\mathbf{b}, \mathbf{d}, \mathbf{f}, \mathbf{h}, \mathbf{j})$ after 5 weeks of treatment. a, b AA; c, d EPA; e, f DHA; g, h PD1; i, j 15d$\mathrm{PgJ}_{2}$. Data are expressed as relative concentration of individual lipids adjusted to wet weight $(\mathrm{cHF}=1)$ and expressed as means $\pm \mathrm{SEM} ; n=3$. White bars, $\mathrm{cHF}$ or $\mathrm{cHF}+\mathrm{CR}$; black bars, $\mathrm{cHF}+\mathrm{F}$ or $\mathrm{cHF}+\mathrm{F}+\mathrm{CR}$. ${ }^{\mathrm{a}}$, , ${ }^{\mathrm{c}}$ Significant differences (ANOVA) compared with $\mathrm{cHF}, \mathrm{cHF}+\mathrm{F}, \mathrm{cHF}+$ $\mathrm{CR}$, respectively. For complete results, see ESM Table 3

response of plasma levels of NEFA and glucose to FASTED to RE-FED transition and the glucose-induced increase in RQ. This improvement of metabolic flexibility correlated with changes in body weight, adiposity and glycaemic control in accordance with the notion that metabolic flexibility is closely associated with insulin sensitivity [2, 32] and that impaired flexibility represents an early defect in the development of type 2 diabetes [35].

Metabolic syndrome is linked to inflammatory changes in both WAT and liver [1]. In this study, in accordance with the previous findings [17, 18, 21], dietary LC $n-3$ PUFA supplementation resulted in the inhibition of formation of various LC $n$-6 PUFA-derived pro-inflammatory eicosanoids in both tissues as well as in the induction of the antiinflammatory molecules. In WAT, in contrast to the liver, the levels of EPA, DHA, AA and their active metabolites, including the anti-inflammatory molecules PD1 and prostaglandin $15 \mathrm{~d}-\mathrm{PGJ}_{2}$, were increased in a synergistic manner by the combination treatment (Fig. 7). A key role of the

enzyme involved in PD1/PDX formation, 12/15 LOX, in adipose tissue inflammation and insulin resistance has been described [36, 37]. The induction of prostaglandin $15 \mathrm{~d}-$ $\mathrm{PGJ}_{2}$ was an unexpected finding as $15 \mathrm{~d}-\mathrm{PGJ}_{2}$ is derived from the metabolism of LC $n-6$ PUFA, and enzymatic formation of LC $n-6$ PUFA metabolites is, in general, inhibited upon LC $n-3$ PUFA supplementation. This suggests that dietary LC $n-3$ PUFA, especially in combination with calorie restriction, selectively activates formation of $15 \mathrm{~d}-\mathrm{PGJ}_{2}$ from prostaglandin D2 (PGD2), the major product of cyclooxygenase (COX) in many tissues [34],

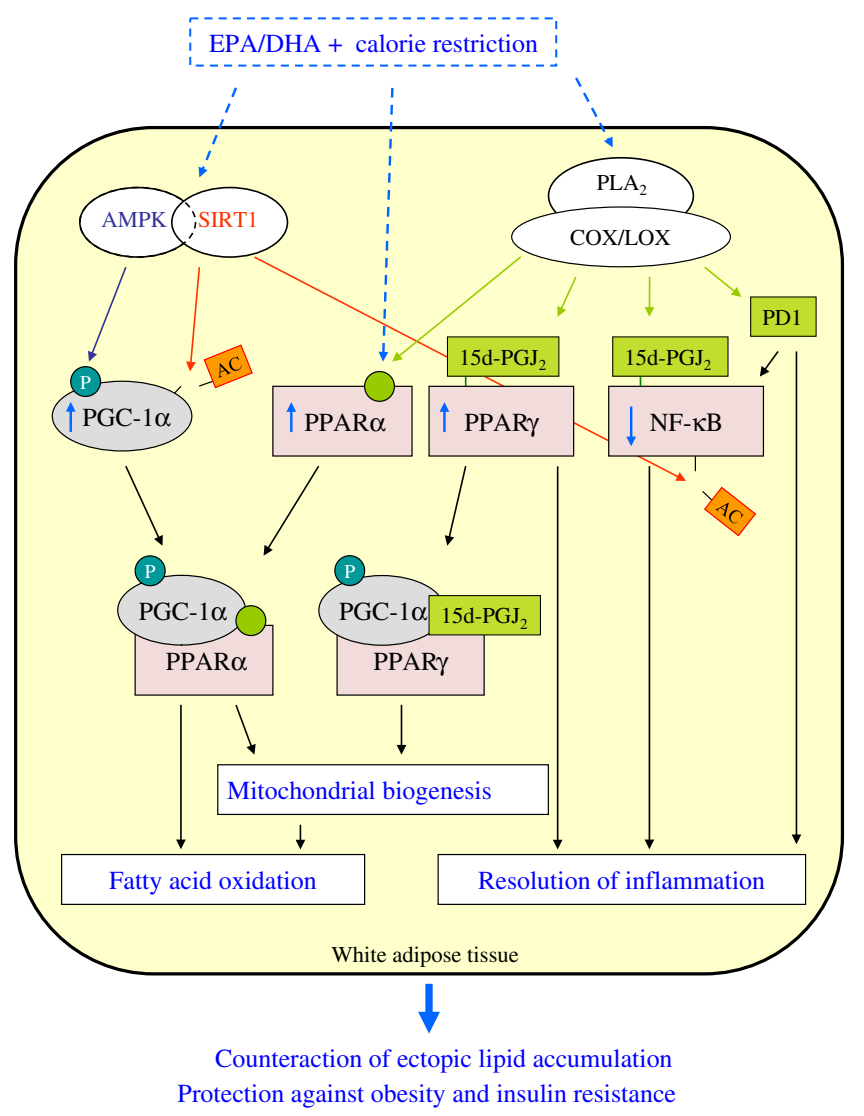

Fig. 8 Putative involvement of AMPK/SIRT1 signalling, 15d-PGJ and PD1 in the additive metabolic and anti-inflammatory effects of the combination of LC n-3 PUFA and calorie restriction in adipose tissue. Dietary intake of LC $n-3$ PUFA combined with calorie restriction activates AMPK/SIRT1 signalling pathway and synergistically induces production of anti-inflammatory and pro-resolving lipid mediators by COX/LOX enzymatic systems. AMPK and SIRT1 can increase activity of transcriptional co-activator PGC- $1 \alpha$ by phosphorylation and de-acetylation, respectively. PGC- $1 \alpha$ can enhance transcriptional activity of PPAR nuclear receptors, resulting in higher mitochondrial oxidative capacity and induction of FA catabolism in situ in white fat. Simultaneously, unsaturated FAs (light green circle) as well as their active metabolites (lipid mediators) can also activate directly PPAR $\alpha$ and PPAR $\gamma$ (e.g. 15d-PGJ ${ }_{2}$ ). Lipid mediators are formed after the release of FAs from membrane phospholipids and can inhibit the NF$\mathrm{\kappa B}$ signalling pro-inflammatory pathway $\left(15 \mathrm{~d}-\mathrm{PGJ}_{2}, \mathrm{PD} 1\right)$ or induce the resolution phase of inflammation (PD1). Of note, SIRT1 can also interfere with NF- $\mathrm{KB}$ signalling. $\mathrm{AC}$, acetyl group; $\mathrm{P}$, phosphate 
reflecting possibly the ability of EPA- and DHA-derived peroxyl radicals to favour the formation of 'less proinflammatory' peroxidation products derived form AA [38].

Here we suggest for the first time that $15 \mathrm{~d}-\mathrm{PGJ}_{2}$ represents an important mediator of LC $n$-3 PUFA effects. $15 \mathrm{~d}-\mathrm{PGJ}_{2}$ can modulate the activity of various signalling molecules by covalent binding and their subcellular localisation [34], including various components of the NF- $\mathrm{kB}$ signalling pathway $[19,39]$. Moreover, $15 \mathrm{~d}-\mathrm{PGJ}_{2}$ is the most potent endogenous ligand for PPAR $\gamma[40,41]$. Interestingly, DHA is a precursor for anti-inflammatory electrophilic cyclopentenone neuroprostanes in macrophages [20] and electrophilic oxo-derivatives generated by COX-2 reactions [19], which can act similarly to $15 \mathrm{~d}-\mathrm{PGJ}_{2}$. Thus, the activation of PPAR $\gamma$ via $15 \mathrm{~d}-\mathrm{PGJ}_{2}$ binding could be responsible for the additive effects of the combination treatment on adipose tissue energy and lipid metabolism. This idea is supported by the fact that rosiglitazone, a PPAR $\gamma$ ligand, increases PPAR $\gamma$ coactivator $1 \alpha(\mathrm{PGC}-1 \alpha)$ production, mitochondrial mass, palmitate oxidation and mitochondrial uncoupling protein 1 (UCP1) in the adipose tissue of genetically obese $o b / o b$ mice [42].

It has been found that brown adipocyte-like cells originating from rosiglitazone-treated epididymal WAT cell precursors represent a new subtype of adipocytes, called 'brite' cells, which differ from classic white and brown adipocytes, but possess mitochondrial UCP1-mediated thermogenesis [43]. Recent studies [44, 45] demonstrated the involvement of COX-2 in the induction of these fatburning cells and the importance of the COX-2-mediated mechanisms for the resistance to dietary obesity in mice. Our results convincingly demonstrate a marked induction of mitochondrial oxidative capacity in permeabilised adipocytes isolated from epididymal fat in response to mild calorie restriction combined with LC $n-3$ PUFA intake, using succinate as the optimum fuel [46]. Moreover, changes in palmitate oxidation in both intact isolated adipocytes and in fat fragments document induction of energy expenditure by the combination treatment. Importantly, these changes occurred even in the absence of UCP1, depending probably on the simultaneous activation of PPAR $\alpha /$ PGC- $1 \alpha$ and PPAR $\gamma$ signalling (Fig. 8). Induction of futile substrate cycling in adipocytes by this mechanism [7] might explain the increased lipid catabolism in the absence of mitochondrial uncoupling. This idea is consistent with our current findings that the combination treatment increases capacity for de novo lipogenesis in epididymal fat, both at the level of gene expression and biochemical activity. In adult mice reared at $20^{\circ} \mathrm{C}$, total oxidative capacity in WAT represents $\sim 30-50 \%$ of brown adipose oxidative capacity [10] indicating that energy expenditure in WAT may influence total energy balance (see Introduction). Even small but persistent changes in
WAT energy expenditure, undetectable using indirect calorimetry, could influence body weight substantially. Fatdepot-specific differences affecting the inducibility of energy-dissipating adipocytes should be explored further. In addition to the stimulation of lipid catabolism in WAT, FA oxidation in liver-but not in skeletal muscle-could contribute to the whole-body effects of the combination treatment.

We have demonstrated previously that AMP-activated protein kinase (AMPK), a cellular energy sensor, is involved in the effects of LC $n$-3 PUFA on hepatic lipid and glucose metabolism [30] and that it is activated in WAT by LC $n$-3 PUFA [47]. AMPK activation in adipocytes results in increased mitochondrial biogenesis and lipid catabolism [4, 48]. Moreover, AMPK closely interacts with deacetylase sirtuin 1 (SIRT1), which controls metabolic processes in response to calorie restriction and exerts antiinflammatory effects in WAT [49]. Therefore, AMPK/SIRT1 signalling is probably involved in the additive metabolic and anti-inflammatory effects of the combination treatments in epididymal WAT (Fig. 8).

In summary, dietary LC $n-3$ PUFA augment the antiobesity effects of mild calorie restriction in mice while improving lipid metabolism and glucose homeostasis. These effects are probably reflected by the large synergistic induction of mitochondrial FA oxidation in WAT, linked to a suppression of low-grade inflammation of this tissue. The synergistic induction of specific anti-inflammatory lipid mediators, namely $15 \mathrm{~d}-\mathrm{PGJ}_{2}$, the LC $n-6$ PUFA metabolite, and PD1, the LC $n-3$ PUFA metabolite, may underlie both the anti-inflammatory and metabolic effects of the combination treatment in WAT. Further exploration of the strategy to target WAT by combining two complementary and physiological approaches, i.e. dietary intake of LC $n-3$ PUFA and mild restriction of energy intake, may be valuable for the prevention and treatment of metabolic syndrome.

Acknowledgements This work was supported by the research project of the Ministry of Education, Youth and Sports (1M6837805002) and by the Czech Science Foundation (303/08/ 0664). Further support includes a grant from EPAX A.S. (Aalesund, Norway), COST action FA0602 and the research project AV0Z 50110509. We thank J. Bemova, S. Hornova and D. Salkova (Institute of Physiology AS CR, Prague) for technical assistance and U. Jahn (Institute of Organic Chemistry and Biochemistry AS CR, Prague, Czech Republic) for critical reading of the manuscript.

P.F. contributed to the conception and design of experiments, analysis and interpretation of data, and drafted the manuscript; R.R. and M.R. contributed to the conception and design of experiments, analysis and interpretation of data, and revising the manuscript; M.H., P.J., P.Z., V.K., Z.M.J., E.P., O.K., M.S., G.T. and V.M-A. contributed to the analysis and interpretation of data, and revising the manuscript; and J.K. coordinated the research, contributed to the conception and design of experiments, and drafted the manuscript. All authors approved the final version of the manuscript. 
Duality of interest The authors declare that there is no duality of interest associated with this manuscript.

\section{References}

1. Virtue S, Vidal-Puig A (2008) It's not how fat you are, it's what you do with it that counts. PLoS Biol 6:e237

2. Galgani JE, Moro C, Ravussin E (2008) Metabolic flexibility and insulin resistance. Am J Physiol Endocrinol Metab 295:E1009E1017

3. Nisoli E, Tonello C, Cardile A et al (2005) Calorie restriction promotes mitochondrial biogenesis by inducing the expression of eNOS. Science 310:314-317

4. Matejkova O, Mustard KJ, Sponarova J et al (2004) Possible involvement of AMP-activated protein kinase in obesity resistance induced by respiratory uncoupling in white fat. FEBS Lett 569:245-248

5. Orci L, Cook WS, Ravazzola M et al (2004) Rapid transformation of white adipocytes into fat-oxidizing machines. Proc Natl Acad Sci USA 101:2058-2063

6. Jaworski K, Ahmadian M, Duncan RE et al (2009) AdPLA ablation increases lipolysis and prevents obesity induced by highfat feeding or leptin deficiency. Nat Med 15:159-168

7. Langin D (2010) Recruitment of brown fat and conversion of white into brown adipocytes: strategies to fight the metabolic complications of obesity? Biochim Biophys Acta 1801:372376

8. Yehuda-Shnaidman E, Buehrer B, Pi J, Kumar N, Collins S (2010) Acute stimulation of white adipocyte respiration by PKA-induced lipolysis. Diabetes 59:2474-2483

9. Rossmeisl M, Syrovy I, Baumruk F, Flachs P, Janovska P, Kopecky J (2000) Decreased fatty acid synthesis due to mitochondrial uncoupling in adipose tissue. FASEB J 14:17931800

10. Kopecky J, Rossmeisl M, Hodny Z, Syrovy I, Horakova M, Kolarova P (1996) Reduction of dietary obesity in the aP2-Ucp transgenic mice: mechanism and adipose tissue morphology. Am J Physiol 270:E776-E786

11. Flachs P, Rossmeisl M, Bryhn M, Kopecky J (2009) Cellular and molecular effects of n-3 polyunsaturated fatty acids on adipose tissue biology and metabolism. Clin Sci 116:1-16

12. Kromhout D, Giltay EJ, Geleijnse JM (2010) n-3 fatty acids and cardiovascular events after myocardial infarction. N Engl J Med 363:2015-2026

13. Flachs P, Horakova O, Brauner P et al (2005) Polyunsaturated fatty acids of marine origin upregulate mitochondrial biogenesis and induce beta-oxidation in white fat. Diabetologia 48:23652375

14. Jolly CA, Muthukumar A, Avula CP, Troyer D, Fernandes G (2001) Life span is prolonged in food-restricted autoimmuneprone (NZB x NZW)F(1) mice fed a diet enriched with (n-3) fatty acids. J Nutr 131:2753-2760

15. Todoric J, Loffler $M$, Huber $J$ et al (2006) Adipose tissue inflammation induced by high-fat diet in obese diabetic mice is prevented by $n-3$ polyunsaturated fatty acids. Diabetologia 49:2109-2119

16. Kuda O, Jelenik T, Jilkova Z et al (2009) n-3 Fatty acids and rosiglitazone improve insulin sensitivity through additive stimulatory effects on muscle glycogen synthesis in mice fed a high-fat diet. Diabetologia 52:941-951

17. Gonzalez-Periz A, Horrillo R, Ferre N et al (2009) Obesityinduced insulin resistance and hepatic steatosis are alleviated by omega-3 fatty acids: a role for resolvins and protectins. FASEB J 23:1946-1957
18. White PJ, Arita M, Taguchi R, Kang JX, Marette A (2010) Transgenic restoration of long-chain $n-3$ fatty acids in insulin target tissues improves resolution capacity and alleviates obesitylinked inflammation and insulin resistance in high-fat-fed mice. Diabetes 59:3066-3073

19. Groeger AL, Cipollina C, Cole MP et al (2010) Cyclooxygenase-2 generates anti-inflammatory mediators from omega-3 fatty acids. Nat Chem Biol 6:433-441

20. Musiek ES, Brooks JD, Joo M et al (2008) Electrophilic cyclopentenone neuroprostanes are anti-inflammatory mediators formed from the peroxidation of the omega- 3 polyunsaturated fatty acid docosahexaenoic acid. J Biol Chem 283:1992719935

21. Gonzalez-Periz A, Planaguma A, Gronert K et al (2006) Docosahexaenoic acid (DHA) blunts liver injury by conversion to protective lipid mediators: protectin D1 and 17S-hydroxyDHA. FASEB J 20:2537-2539

22. Mori TA, Bao DQ, Burke V, Puddey IB, Watts GF, Beilin LJ (1999) Dietary fish as a major component of a weight-loss diet: effect on serum lipids, glucose, and insulin metabolism in overweight hypertensive subjects. Am J Clin Nutr 70:817-825

23. Ramel A, Martinez A, Kiely M, Morais G, Bandarra NM, Thorsdottir I (2008) Beneficial effects of long-chain n-3 fatty acids included in an energy-restricted diet on insulin resistance in overweight and obese European young adults. Diabetologia 51:1261-1268

24. Krebs JD, Browning LM, McLean NK et al (2006) Additive benefits of long-chain $n-3$ polyunsaturated fatty acids and weightloss in the management of cardiovascular disease risk in overweight hyperinsulinaemic women. Int J Obes 30:1535-1544

25. Rossmeisl M, Jelenik T, Jilkova $Z$ et al (2009) Prevention and reversal of obesity and glucose intolerance in mice by DHA derivatives. Obesity 17:1023-1031

26. Kus V, Prazak T, Brauner P et al (2008) Induction of muscle thermogenesis by high-fat diet in mice: association with obesityresistance. Am J Physiol Endocrinol Metab 295:E356-E367

27. Flachs P, Mohamed-Ali V, Horakova O et al (2006) Polyunsaturated fatty acids of marine origin induce adiponectin in mice fed high-fat diet. Diabetologia 49:394-397

28. van Schothorst EM, Flachs P, Franssen-van Hal NL et al (2009) Induction of lipid oxidation by polyunsaturated fatty acids of marine origin in small intestine of mice fed a high-fat diet. BMC Genom 10:110

29. Baumruk F, Flachs P, Horakova M, Floryk D, Kopecky J (1999) Transgenic UCP1 in white adipocytes modulates mitochondrial membrane potential. FEBS Lett 444:206-210

30. Jelenik T, Rossmeisl M, Kuda O et al (2010) AMP-activated protein kinase $\alpha 2$ subunit is required for the preservation of hepatic insulin sensitivity by $n-3$ polyunsaturated fatty acids. Diabetes 59:2737-2746

31. Ruhl R (2006) Method to determine 4-oxo-retinoic acids, retinoic acids and retinol in serum and cell extracts by liquid chromatography/diode-array detection atmospheric pressure chemical ionisation tandem mass spectrometry. Rapid Commun Mass Spectrom 20:2497-2504

32. Storlien L, Oakes ND, Kelley De (2004) Metabolic flexibility. Proc Nutr Soc 63:363-368

33. Cinti S, Mitchell G, Barbatelli G et al (2005) Adipocyte death defines macrophage localization and function in adipose tissue of obese mice and humans. J Lipid Res 46:2347-2355

34. Scher JU, Pillinger MH (2005) 15d-PGJ2: the anti-inflammatory prostaglandin? Clin Immunol 114:100-109

35. Corpeleijn E, Mensink M, Kooi ME, Roekaerts PM, Saris WH, Blaak EE (2008) Impaired skeletal muscle substrate oxidation in glucose-intolerant men improves after weight loss. Obesity $16: 1025-1032$ 
36. Chakrabarti SK, Cole BK, Wen Y, Keller SR, Nadler JL (2009) 12/ 15-lipoxygenase products induce inflammation and impair insulin signaling in 3T3-L1 adipocytes. Obesity 17:1657-1663

37. Sears DD, Miles PD, Chapman J et al (2009) 12/15-lipoxygenase is required for the early onset of high fat diet-induced adipose tissue inflammation and insulin resistance in mice. PLoS One 4: e 7250

38. Davis TA, Gao L, Yin H, Morrow JD, Porter NA (2006) In vivo and in vitro lipid peroxidation of arachidonate esters: the effect of fish oil omega-3 lipids on product distribution. J Am Chem Soc 128:14897-14904

39. Rossi A, Kapahi P, Natoli G et al (2000) Anti-inflammatory cyclopentenone prostaglandins are direct inhibitors of IkappaB kinase. Nature 403:103-118

40. Forman BM, Tontonoz P, Chen J, Brun RP, Spiegelman BM, Evans RM (1995) 15-Deoxy-delta 12, 14-prostaglandin J2 is a ligand for the adipocyte determination factor PPAR gamma. Cell $83: 803-812$

41. Kliewer SA, Lenhard JM, Willson TM, Patel I, Morris DC, Lehmann JM (1995) A prostaglandin J2 metabolite binds peroxisome proliferator-activated receptor gamma and promotes adipocyte differentiation. Cell 83:813-819

42. Wilson-Fritch L, Nicoloro S, Chouinard M et al (2004) Mitochondrial remodeling in adipose tissue associated with obesity and treatment with rosiglitazone. J Clin Invest 114:1281-1289
43. Nedergaard J, Cannon B (2010) The changed metabolic world with human brown adipose tissue: therapeutic visions. Cell Metab $11: 268-272$

44. Madsen L, Pedersen LM, Lillefosse HH et al (2010) UCP1 induction during recruitment of brown adipocytes in white adipose tissue is dependent on cyclooxygenase activity. PLoS One 5:e11391

45. Vegiopoulos A, Muller-Decker K, Strzoda D et al (2010) Cyclooxygenase- 2 controls energy homeostasis in mice by de novo recruitment of brown adipocytes. Science 328:1158-1161

46. Wang T, Si Y, Shirihai OS et al (2010) Respiration in adipocytes is inhibited by reactive oxygen species. Obesity 18:1493-1502

47. Kopecky J, Rossmeisl M, Flachs P et al (2009) n-3 PUFA: bioavailability and modulation of adipose tissue function. Proc Nutr Soc 68:361-369

48. Gaidhu MP, Fediuc S, Anthony NM et al (2009) Prolonged AICAR-induced AMP-kinase activation promotes energy dissipation in white adipocytes: novel mechanisms integrating HSL and ATGL. J Lipid Res 50:704-715

49. Yoshizaki T, Milne JC, Imamura T et al (2009) SIRT1 exerts antiinflammatory effects and improves insulin sensitivity in adipocytes. Mol Cell Biol 29:1363-1374

50. Larsson SC, Kumlin M, Ingelman-Sundberg M, Wolk A (2004) Dietary long-chain $n-3$ fatty acids for the prevention of cancer: a review of potential mechanisms. Am J Clin Nutr 79:935-945 